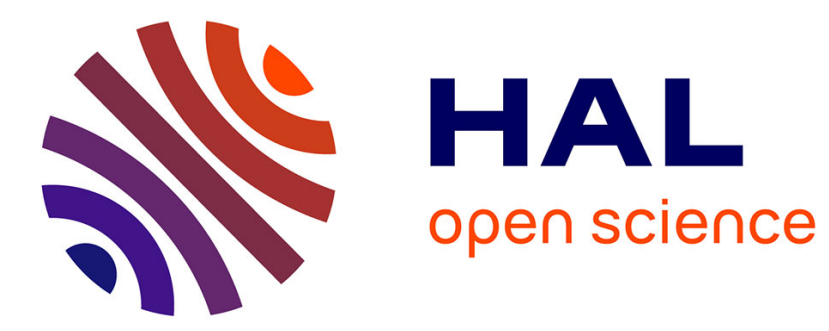

\title{
Apparent synfolding magnetization as a result of overlap of pre- and post-folding magnetizations
}

Nadir Halim, Jean-Pascal Cogné, Vincent Courtillot, Yan Chen

\section{To cite this version:}

Nadir Halim, Jean-Pascal Cogné, Vincent Courtillot, Yan Chen. Apparent synfolding magnetization as a result of overlap of pre- and post-folding magnetizations. Geophysical Research Letters, 1996, 23

(24), pp.3523-3526. 10.1029/96GL03254 . insu-00717704

\section{HAL Id: insu-00717704 \\ https://hal-insu.archives-ouvertes.fr/insu-00717704}

Submitted on 13 Jul 2012

HAL is a multi-disciplinary open access archive for the deposit and dissemination of scientific research documents, whether they are published or not. The documents may come from teaching and research institutions in France or abroad, or from public or private research centers.
L'archive ouverte pluridisciplinaire HAL, est destinée au dépôt et à la diffusion de documents scientifiques de niveau recherche, publiés ou non, émanant des établissements d'enseignement et de recherche français ou étrangers, des laboratoires publics ou privés. 


\title{
Apparent synfolding magnetization as a result of overlap of pre- and post-folding magnetizations
}

\author{
Nadir Halim, Jean Pascal Cogné and Vincent Courtillot \\ Institut de Physique du Globe de Paris, Paris, France
}

Yan Chen

Laboratoire de Géologie Structurale, Université d'Orléans, Orléans, France

\begin{abstract}
In most rocks, Natural Remanent Magnetization (NRM) can involve two or more superimposed components. Demagnetizations hopefully result in the separation of these components, which may then be resolved using least-squares regression methods. In a study of Cretaceous redbed sites from Qaidam (China), thermal demagnetization of most specimens revealed 3 rectilinear segments in orthogonal plots, giving the appearance of a 3-component magnetization. In order to help deciding if the intermediate straight segments could have resulted from overlap between post-folding low temperature (LTC) and pre-folding high temperature components (HTC), we modeled the overlap using a priori information on the directions and relative intensities of LTC and HTC derived from the actual observations. We constructed typical synthetic Zijderveld (1967) diagrams for each site, which could be compared with those obtained from the real samples. We conclude for the Qaidam samples that the intermediate temperature component (ITC) is most likely an artefact resulting from overlap between the LTC and HTC.
\end{abstract}

\section{Introduction.}

Demagnetization techniques routinely used by paleomagnetists are expected to either confirm the primary nature of a natural remanent magnetization (NRM) or to unravel successive phases of remagnetization and overprinting. When demagnetization steps are suitably chosen, demagnetization paths can often be divided into rectilinear segments in orthogonal projection, and the directions of individual components determined with a principal component line fitting method (Kirschvink, 1980). The number of segments is usually taken to be the number of magnetization components (although, as noted by R. Butler pers. comm., 1996 - the degree of difficulty in deciphering NRM increases as some rather large power of the number of components). Overlap of unblocking temperature or coercivity spectra tends to produce a curved trajectory on the vector component diagrams within the interval of overlap. This is how such overlaps are generally recognized (e.g. Dunlop, 1979).

During thermal demagnetization of Cretaceous redbeds from the Gansu Corridor, in the Qaidam block (China; Halim et al, in preparation), we obtained Zijderveld diagrams consisting of 3 rather clear linear segments in 9 out of 13 sites (Figure 1).

Copyright 1996 by the American Geophysical Union.

Paper number 96GL03254.

0094-8534/96/96GL-03254\$05.00
The first segment represents a lower temperature component (LTC), unblocked by $280-350^{\circ} \mathrm{C}$, which is close to the present earth field (PEF) direction; the third segment represents a higher temperature component (HTC) which becomes unblocked above $550^{\circ} \mathrm{C}$ (see Table 1). The intermediate segment can be interpreted in (at least) two different manners. It could correspond to an intermediate temperature component (ITC) with an unblocking temperature spectrum ranging from a lower temperature between 300 and $400^{\circ} \mathrm{C}$ to an upper temperature between 550 and $600^{\circ} \mathrm{C}$. Alternately, it could have resulted from overlap between the HTC and the LTC, hence be an artefact with no useful paleomagnetic meaning. But then this would be a rather unusual overlap with straight rather than curved trajectory. The purpose of this letter is to briefly report

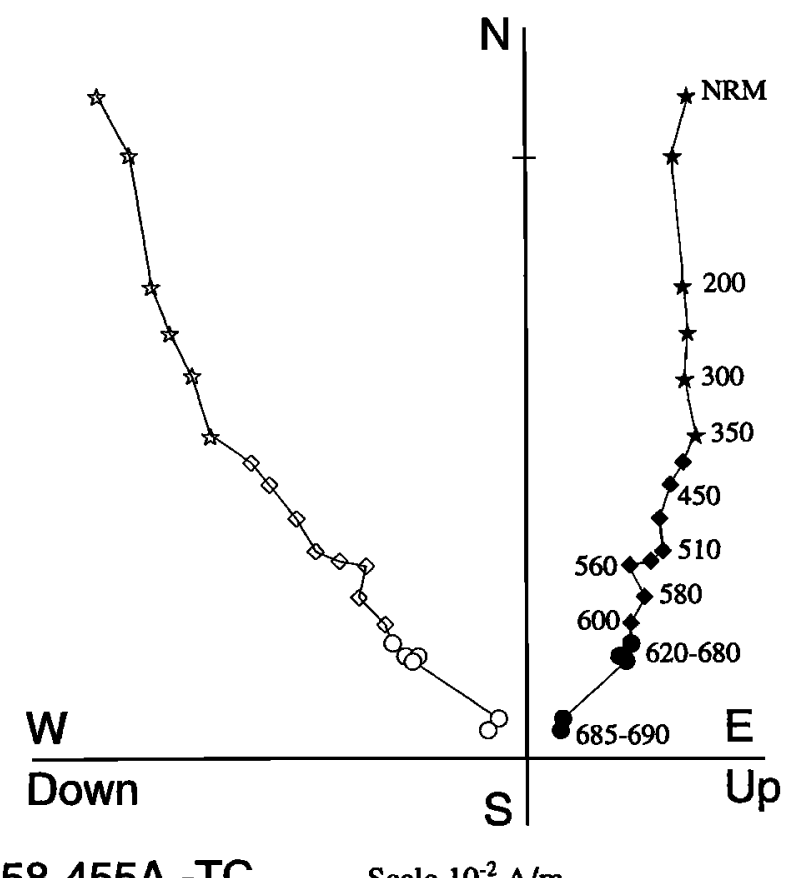

\section{8-455A -TC Scale $10^{-2} \mathrm{~A} / \mathrm{m}$}

Figure 1. A typical demagnetization diagram (Zijderveld, 1967) from a Cretaceous redbed specimen (58-455A) from the Qaidam block (China; Halim et al, in preparation) displaying three quasi-linear demagnetization segments, apparently corresponding to three distinct components of magnetization at lower (LTC, stars), intermediate (ITC, diamonds) and higher (HTC, circles) temperatures. Some demagnetization temperature steps are indicated. Correction for bedding has been applied (see table 1). Closed (resp. opened) symbols are for projections onto the horizontal (resp. NS-vertical) plane. 


\begin{tabular}{|c|c|c|c|c|c|c|c|c|c|c|}
\hline \multirow[t]{2}{*}{ Sule } & \multicolumn{2}{|c|}{ Bedding } & \multicolumn{4}{|c|}{ LTC } & \multicolumn{4}{|c|}{ HTC } \\
\hline & Strike & Dip & $T_{11}-T_{f 1}$ & M & D & I & $T_{12}-T_{12}$ & & D & 1 \\
\hline $\begin{array}{l}32 \\
33 \\
35 \\
55 \\
56 \\
58 \\
59 \\
60\end{array}$ & $\begin{array}{l}38 \\
157 \\
126 \\
118 \\
118 \\
249 \\
261 \\
263\end{array}$ & $\begin{array}{l}18 \\
75 \\
32 \\
42 \\
42 \\
44 \\
52 \\
56\end{array}$ & $\begin{array}{l}0.580 \\
0.580 \\
0.580 \\
0.580 \\
0-580 \\
0.580 \\
0.580 \\
0.580\end{array}$ & $\begin{array}{l}0.30 \\
0.40 \\
0.21 \\
1.45 \\
1.82 \\
7.68 \\
2.63 \\
2.04\end{array}$ & $\begin{array}{l}29.1 \\
29.9 \\
21.2 \\
11.5 \\
17.2 \\
10.6 \\
7.1 \\
6.5\end{array}$ & $\begin{array}{l}52.3 \\
45.5 \\
56.8 \\
54.5 \\
43.4 \\
58.6 \\
57.0 \\
57.5\end{array}$ & $\begin{array}{l}350-680 \\
350-680 \\
350-680 \\
350-680 \\
350-680 \\
350-680 \\
350-680 \\
350-680\end{array}$ & $\begin{array}{l}3.40 \\
0.39 \\
0.33 \\
2.60 \\
1.03 \\
9.51 \\
3.47 \\
3.59\end{array}$ & $\begin{array}{l}43.5 \\
58.9 \\
34.3 \\
21.2 \\
17.7 \\
89.0 \\
99.6 \\
114.6\end{array}$ & $\begin{array}{l}46.5 \\
-223 \\
176 \\
15.5 \\
31.9 \\
45.6 \\
41.2 \\
438\end{array}$ \\
\hline
\end{tabular}

Charactenstics of low (LTC) and hagh (HTC) temperenure components (in situ coondinates) for 8 sites of Cretsceous redbeds from Qmidam (China; Hallim a al, in prepentation). Site number, bedding struke (s) and dip (d) are

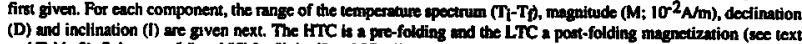
and Table 2). Subsconpts " $I$ " and "f" for "initul" and "find".

our analysis and modelling of this problem, which does not seem to have been previously encountered. A full report of the Qaidam study is given elsewhere (Halim et al, in preparation). In the following, the intermediate linear part of the vector plots is termed ITC, with no a priori implied interpretation as to whether this is a real component or an artefact.

\section{Analysis}

The ITC was determined on the intermediate temperature linear portions of the demagnetization diagrams, where it was clearly not parallel to either the LTC or the HTC, at the specimen level. Site-mean directions of the ITC from the 9 sites in which it was isolated are illustrated in equal-area projection in Figure 2 ( $a$ and $b$ ), which shows that data cluster upon total unfolding, although significant scatter remains.
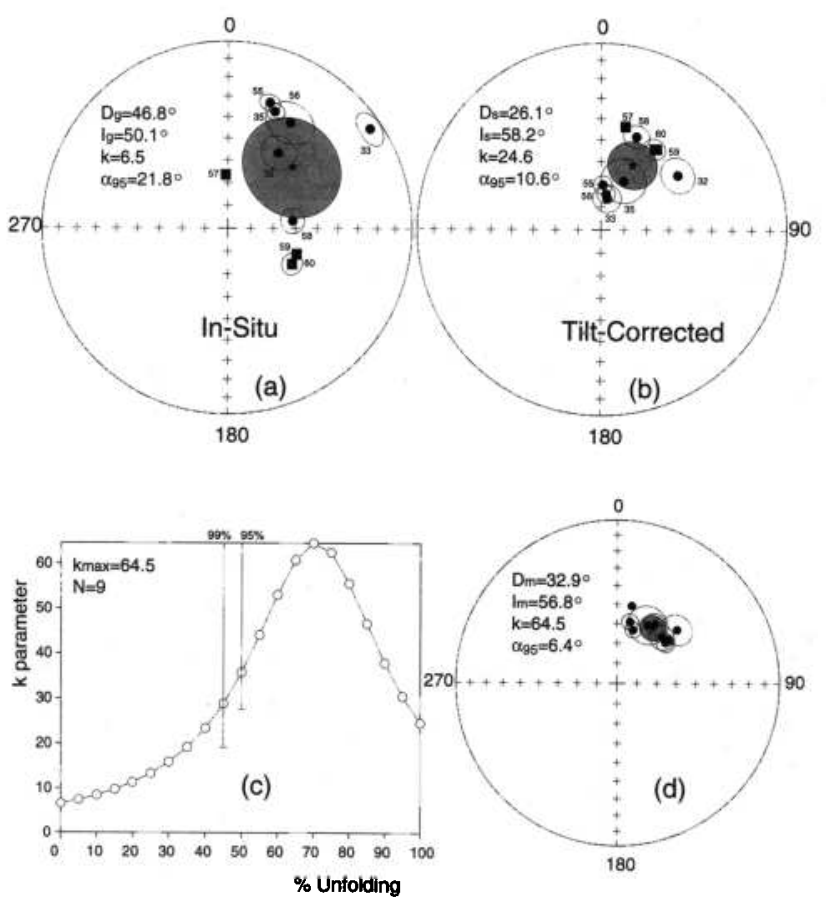

Figure 2. Equal area projection of the apparent intermediate temperature component (ITC) site-means and overall mean (star with shaded $95 \%$ cone of confidence) obtained from the Cretaceous redbeds sites in Qaidam (China; Halim et al, in preparation) before (a) and after (b) bedding correction. Squares (resp. dots) are site-mean directions from North (resp. South) dipping limbs. (c) stepwise unfolding of the observed apparent ITC, showing a maximum Fisher (1953) precision parameter $\mathrm{k}$ for $70 \%$ of unfolding ( $\mathrm{N}=9$ sites); the resulting site-mean directions and overall mean are shown in (d).
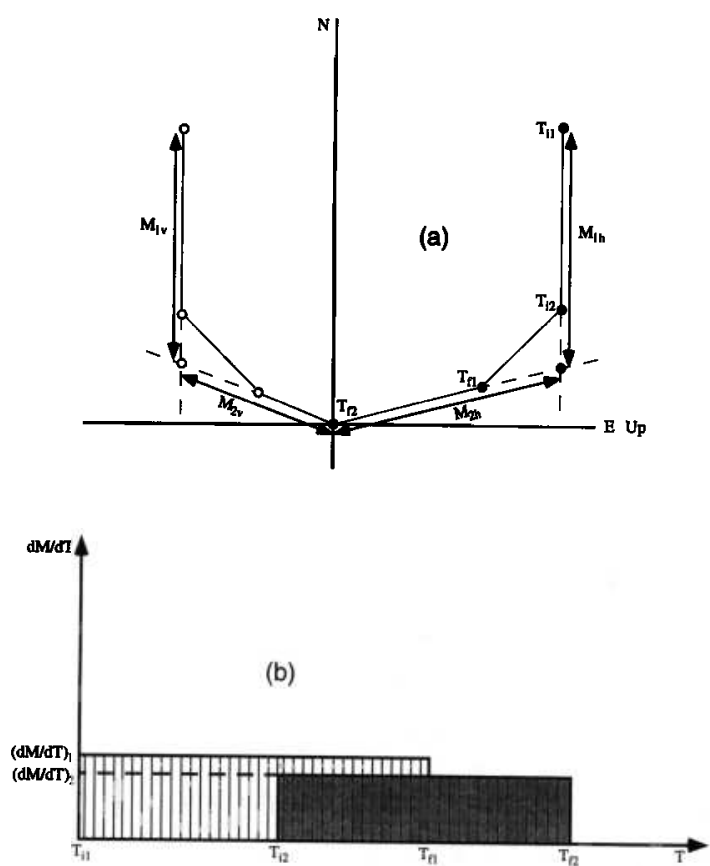

Figure 3. (a) Simplified schematic representation of the determination of LTC and HTC intensities; $M_{1 v}$ and $M_{1 h}(l$ resp. $M_{2 v}$ and $M_{2 h}$ ) represent the north-vertical and horizontal components of the lower temperature (resp. higher temperature) component. (b) A simple model of the uniform overlapping temperature spectra of the LTC (between $T_{i 1}$ and $T_{f 1}$ ) and HTC (between $T_{i 2}$ and $T_{f 2}$ ), with respective magnetization densities $(\mathrm{dM} / \mathrm{dT})_{1}$ and $(\mathrm{dM} / \mathrm{dT})_{2}$. The integral of each spectrum (area of the corresponding rectangle) is determined from the intensities in (a). Same conventions as in Figure 1.

Average directions before and after full bedding correction are respectively $\mathrm{D}_{\mathrm{g}}=46.8^{\circ}, \mathrm{I}_{\mathrm{g}}=50.1^{\circ}\left(\alpha_{95}=21.8^{\circ}\right)$, and $\mathrm{D}_{\mathrm{s}}=26.1^{\circ}$, $I_{S}=58.2^{\circ}\left(\alpha 95=10.6^{\circ}\right)$. Furthermore, it may be seen that data from north dipping limbs (sites 57, 59, 60; squares in Fig.2a and $2 b$ ) cross over data from south dipping limbs (all other sites; circles in Fig. $2 \mathrm{a}$ and $2 \mathrm{~b}$ ) upon unfolding. This holds not only for sites from different limbs, but also for data from south dipping limbs with different dip angles (see in particular sites 32, 33, and 35). This kind of behaviour is often interpreted as resulting from a remagnetization during folding. We thus performed a progressive stepwise unfolding of these data (in 5\% steps), and followed the evolution of the grouping through the $\mathrm{k}$ precision parameter (Fisher, 1953) as a function of unfolding percentage. The results of this stepwise unfolding are shown in Figure 2(c and d). Maximum clustering occurs at $70 \%$ of unfolding, with $\mathrm{k}=64.5$. This clustering is

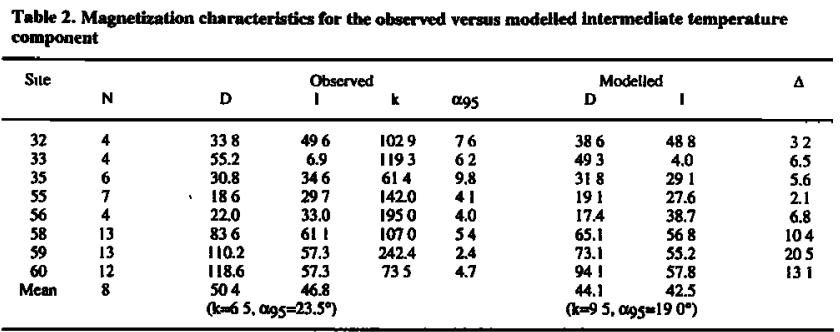

Mean declination and inclinstion (in situ coondinates) and statustical parameters of the observed and modelled apparen intermediate temperature component (ITC). N is the number of specrmens used in each ante. $k$ and $\alpha_{95}$ are the Fisher precisson pararmeter and the radius of the $95 \%$ cone of confidence for the observed ITC site-means $\Delta$ is the 
significant at the $99 \%$ probability level with respect to uncorrected directions, and at the $95 \%$ probability level with respect to the fully tilt-corrected directions. Following the classical interpretation, we should therefore conclude that the ITCs from this formation are a remagnetization acquired early (about $30 \%$ ) in the folding of this series. The corresponding average ITC direction would be $\mathrm{D}=32.9^{\circ}, \mathrm{I}=56.8^{\circ}\left(\mathrm{k}=64.5^{\text {, }}\right.$ $\alpha_{95}=6.4^{\circ}, \mathrm{N}=9$ ).

For the same sites, the LTC yields a negative fold test (at the $99 \%$ confidence level) and a post-folding direction of $\mathrm{D}_{\mathrm{g}}=15.3^{\circ}, \mathrm{I}_{\mathrm{g}}=53.9^{\circ}\left(\alpha_{95}=5.3^{\circ}\right)$. With bedding correction one finds $D_{S}=353.1^{\circ}, I_{S}=50.3^{\circ}\left(\alpha 95=28.6^{\circ}\right)$. In the same way, the HTC yields a positive fold test (at the $99 \%$ confidence level) and a pre-folding direction of $D_{S}=38.5^{\circ}, I_{S}=50.2^{\circ}$ $\left(\alpha_{95}=11.8^{\circ}\right)$. Before bedding correction, one finds $D_{g}=51.2^{\circ}$, $I_{g}=38.0^{\circ}\left(\alpha_{95}=28.2^{\circ}\right)$. The ITC therefore lies between the pre-folding HTC and post-folding LTC directions and yields an "in-between" apparent synfolding remagnetization test. These observations are of course a cause of some concern. Moreover, a few Zijderveld diagrams do show some amount of curvature.

In effect, if we now go back to the demagnetization curves, we note that the ITCs generally make a small angle with respect to the HTCs at the specimen level. When they are present in a single specimen, LTC, ITC and HTC all have Northerly downward directions. We should therefore consider the possibility that the ITC could result from overlapping unblocking temperature spectra of the LTC and HTC.

\section{Modelling and Discussion}

In order to investigate these possibilities, we have attempted to model the demagnetization behaviour of two components with overlapping spectra, and to compare results from the model to the observed data.

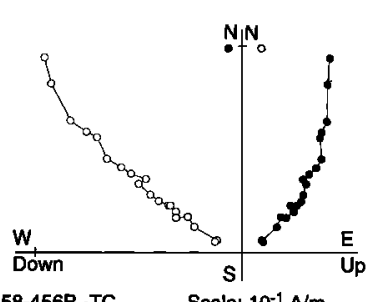

$58-456 \mathrm{~B} \cdot \mathrm{TC}$

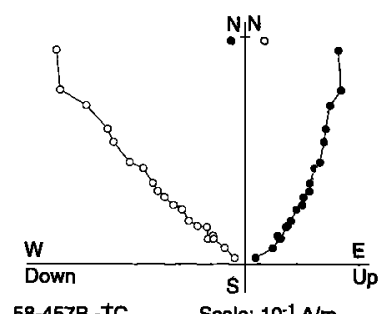

58-457B - TC Scale: $10^{-1} \mathrm{~A} / \mathrm{m}$

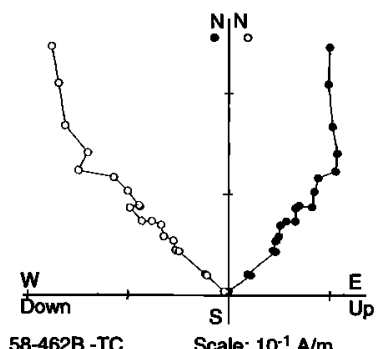

58-462B -TC Scale: $10^{-1} \mathrm{~A} / \mathrm{m}$

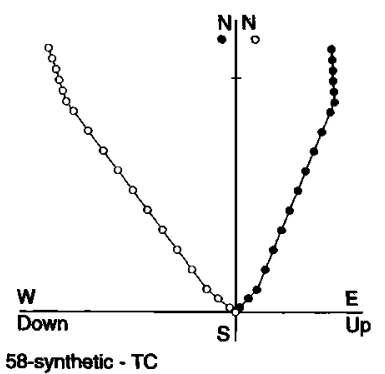

Figure 4. Orthogonal vector plots of three actual and one synthetic demagnetization diagrams for samples from site 58, after tilt correction. The synthetic case is based on the model of Figure 3 where the LTC is assumed to be post-folding and the HTC pre-folding. The slight differences in NRM magnitudes or orientations are due to the fact that the modelled specimen is an average of intensities and directions determined from all specimens of the given site. Same conventions as in Figure 1.
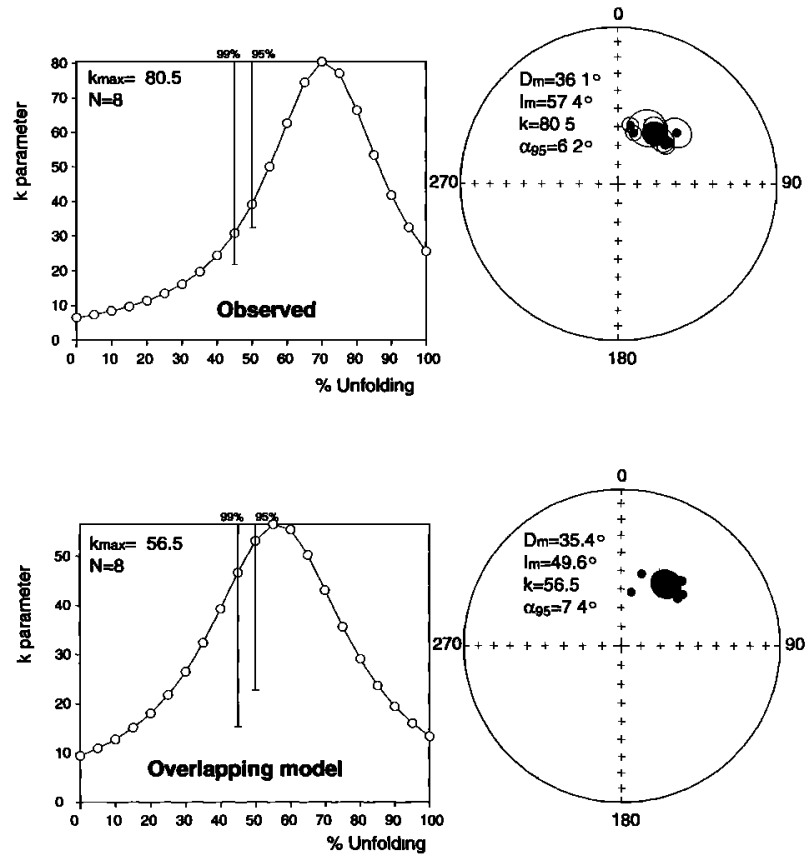

Figure 5. Stepwise unfolding of the observed and modelled apparent intermediate temperature component for the $\mathrm{N}=8$ sites in which the three components LTC, ITC and HTC had been observed. Maximum grouping occurs at $70 \%$ of unfolding for the observed ITC and 55\% of unfolding for the modelled one. The two average directions are close but distinguishable, mostly because of an inclination difference $\left(\Delta \mathrm{I}=7.8^{\circ} \pm 9.7^{\circ}\right.$; see text).

We start by determining the site-mean directions and the average magnitudes of the LTC and HTC for the 8 out of 9 sites where all three LTC, ITC, and HTC were found to co-exist. The intensities of LTC and HTC were estimated graphically, as shown in Figure 3a. The directions of LTC and HTC were continued linearly and intensities evaluated from NRM to the intersection point for the LTC, and from that point to the origin for the HTC. For site 57, both the ITC and HTC were of very small amplitude and rather noisy, and we were unable to determine the intensity of the HTC.

For the purpose of the model, we next made the simple hypothesis that the unblocking temperature spectra were uniform in the range of existence of each component (i.e. $\mathrm{T}_{\mathrm{i}}$ and $T_{f 1}$ for the LTC, $T_{i 2}$ and $T_{f 2}$ for the HTC; see Figure $3 b$ ). A uniform temperature increment $\mathrm{dT}$ was chosen to construct synthetic demagnetization diagrams. The integrals of each spectrum distribution (i.e. the areas of the two corresponding, overlapping, rectangles) were constrained by the intensities as determined in Figure 3a:

$$
\begin{aligned}
& \int_{T_{i 1}}^{T_{f 1}}(d \vec{M} / d T)_{1} d T=\overrightarrow{L T C} \\
& \int_{T_{12}}^{T_{\mathrm{f} 2}}(d \vec{M} / d T)_{2} d T=\overrightarrow{H T C}
\end{aligned}
$$

allowing the determination of the magnetization densities $(\mathrm{dM} / \mathrm{dT})_{1}$ and $(\mathrm{dM} / \mathrm{dT})_{2}$. Given the direction of the LTC and HTC vectors, it is then a simple matter to construct a synthetic Zijderveld demagnetization diagram. 
Table 3: Overall mean magnetization directions for the lower, intermediate and higher temperature components.

\begin{tabular}{cccccccccc}
\hline & D & Ig $_{\mathrm{g}}$ & $\alpha 95$ & D & I & $\alpha 95$ & DS $_{S}$ & IS $_{5}$ & $\alpha_{95}$ \\
\hline LTC & 173 & 535 & 55 & & & & 3494 & 529 & 326 \\
ITC & 504 & 468 & 235 & 361 & 57.4 & 62 & 285 & 601 & 11.1 \\
HTC & 556 & 327 & 28.8 & & & & 435 & 50.5 & 115 \\
\hline
\end{tabular}

Means are calculated for $\mathrm{N}=8$ stes (see text and Tables I and 2) The first three columns give declination (Dg) inclination $\left(I_{g}\right.$ ) and $95 \%$ confidence interval ( $\alpha_{95}$ ) before bedding correction The last three columns give doclination $\left(D_{5}\right)$, inclination $\left(I_{s}\right)$ and $95 \%$ confidence interval $(\alpha 95)$ after bedding correctron The middle columns $\left(D, I, \alpha_{5}\right)$ ate for the ITC only for partial unfolding at 70\%, minımizing $\alpha 95$ (see text and Figure 5). Subscrpts " $\mathrm{g}$ " and " $\mathrm{s}$ " for "geographic" and "stratigraphic" coordinate.

In our study, we selected a temperature increment dT of $20^{\circ} \mathrm{C} ; \mathrm{dM} / \mathrm{dT}, \mathrm{T}_{\mathrm{i}}$, and $\mathrm{T}_{\mathrm{f}}$ corresponding to each pair (LTC, HTC) were obtained from real samples, as listed in Table 1. The LTC was considered to be entirely post-folding and the HTC pre-folding, and the appropriate bedding attitudes were used for each site. We constructed in this way a typical synthetic Zijderveld diagram for each site. Results of this simulation are given in Table 2, where they are compared to the mean ITC in each site. As an example, we present in Figure 4 observed orthogonal vector plots corresponding to three additional specimens from site 58 (see also Figure 1) and the synthetic diagram for that site. As expected from the spectra of Figure 3b, the synthetic vector plots consists of 3 linear portions, which could erroneously be interpreted as three independent magnetization directions. We see in Table 2 that the observed and modelled ITC overall mean for 8 sites are quite similar in geographic coordinates: $\mathrm{D}_{\mathrm{g}}=50.4^{\circ}, \mathrm{I}_{\mathrm{g}}=46.8^{\circ}$ vs $D_{g}=44.1^{\circ}, I_{g}=42.5^{\circ}$. The same is true in stratigraphic coordinates: $D_{S}=28.5^{\circ}, I_{S}=60.1^{\circ}$ vs $D_{S}=27.3^{\circ}, I_{S}=53.5^{\circ}$. When performing stepwise unfolding, the overlapping model gave a maximum $\mathrm{k}$ parameter for the ITC at $55 \%$ of unfolding, confirming that overlap of the two actual directions can produce an apparent synfolding magnetization component (Figure 5). The synthetic ITC would seem to have been acquired after $45 \%$ of folding, and the recorded direction would then be $D=35.4^{\circ}, I=49.6^{\circ}\left(\alpha 95=7.4^{\circ}\right)$. This compares very favorably with the actual data where $\mathrm{k}$ has its maximum value at $70 \%$ of unfolding, and with ITC direction $\mathrm{D}=36.1^{\circ}, \mathrm{I}=57.4^{\circ}$ $\left(\alpha 95=6.2^{\circ}\right)$ (Table 3$)$. The actual and synthetic ITC are slightly different in inclination $\left(\Delta \mathrm{l}=7.8^{\circ} \pm 9.7^{\circ}\right)$, in part because unfolding is not exactly at the same level. Also, the hypotheses for the intensities of LTC and HTC and shape of their unblocking temperature spectra are clearly oversimplifications.

This simple model shows that two magnetization components with overlapping unblocking temperature spectra, one acquired prior to folding and the other after folding, may yield in some cases (that is for certain values of the temperature range and shape of the spectra), a linear magnetization component with apparent intermediate temperature range and an apparent positive synfolding remagnetization test, which is actually an artefact. This rather unusual situation contrasts with the more commonly encountered situation when overlaps produce curved trajectories. Here, the proportions of the high and low stability components removed within each increment of demagnetization stay roughly constant throughout the overlapping interval. Given the data uncertainties, there is no point in devising a more complex and realistic unblocking temperature spectrum for the LTC or HTC. Also, it is reasonable to conclude in the case of our Qaidam data, where the red beds were deposited in the Cretaceous, folded as a result of the Cenozoic India-Asia collision and to some extent overprinted in the direction of the recent field, that the apparent synfolding ITC has no useful geological meaning. We could clearly have been (and were originally) tempted to use this apparently well dated component to deduce a pole and relative displacements of Qaidam with respect to neighbouring blocks as a result of the ongoing collision.

A somewhat related warning was given by Dinarès and McClelland (1991): in that case complete overlap in constant proportions of two magnetization components resulted in a single vector component upon thermal demagnetization. AF demagnetization and Lowrie tests however allowed to separate the two components to some extent. Such tests were unsuccessful in our study (Halim et al, in preparation). We hope that this letter will be yet another cautionary example of some use in other similar studies.

Acknowledgments. This study is part of a cooperation project on the Kunlun mountains between the French Institut National des Sciences de l'Univers and the Ministry of Geology and Mineral Resources of the People's Republic of China. We are grateful to P. McFadden, R. Butler and $V$. DiVenere for careful and very useful reviews. IPGP contribution $\mathrm{n}^{\circ} 1437$.

\section{References}

Dinarès-Turell, J., and McClelland, E., A cautionary tale for paleomagnetists: A spurious apparent single component remanence due to overlap of blocking-temperature spectra of two components, Geophys. Res. Lett., 18, 1297-1300, 1991.

Dunlop, D.J., On the use of Zijderveld vector diagrams in multicomponent paleomagnetic studies, Phys. Earth Planet. Inter., 20, 12-24, 1979.

Fisher, R.A., Dispersion on a sphere, Proc. R. Soc. London, 217, $295-$ 305, 1953.

McElhinny, M.W., Statistical significance of the fold test in paleomagnetism, Geophys. J. R. astr. Soc., 8, 33-40, 1964.

Kirschvink, J.L., The least squares line and plane and the analysis of paleomagnetic data, Geophys. J. R. Astr. Soc., 62, 699-718, 1980.

Zijderveld, J.D.A., A.C. demagnetization of rocks: Analysis of results, in Methods in paleomagnetism, D.W.Collinson, K.M. Creer, and S.K. Runcorn, eds., pp. 254-286, 1967.

N. Halim, Laboratoire de Paléomagnétisme, Institut de Physique du Globe, 4 place Jussieu, 75252 Paris cedex 05, France

J.P. Cogné, Laboratoire de Paléomagnétisme, Institut de Physique du Globe, 4 place Jussieu, 75252 Paris cedex 05, France.

V. Courtillot, Laboratoire de Paléomagnétisme, Institut de Physique du Globe, 4 place Jussieu, 75252 Paris cedex 05, France.

Y. Chen, Laboratoire de Géologie structurale, URA 1366, BP 6759 , 45067 Orléans cedex 2, France.

(Received March 29, 1996; revised September 25, 1996; accepted September 26, 1996.) 